\title{
Association between Low-density lipoprotein cholesterol and occipital periventricular hyperintensities in a group of Chinese patients: an observational study
}

\author{
Dazhi Duan ${ }^{1 *}$, Lin Shen ${ }^{1}$, Chun Cui ${ }^{2}$, Tongsheng Shu ${ }^{2}$ and Jian Zheng ${ }^{1}$
}

\begin{abstract}
Background: While occipital periventricular hyperintensities (OPVHs) are among the most common mild white matter hyperintensities, the clinical factors associated with OPVHs remain unclear. In this study, we investigated the role of clinical factors in development of pure OPVHs.

Methods: This study included 97 patients with OPVHs and 73 healthy controls. Univariate analysis of clinical factors in $\mathrm{OPVH}$ patients and controls was followed by binomial logistic regression analysis to identify clinical factors significantly associated with OPVHs.

Result: Univariate analysis indicated that age, total cholesterol (TC), low-density lipoprotein cholesterol (LDL-C) and apolipoprotein-B (Apo-B) levels differed significantly between the OPVH patients and controls $(p<0.05)$. Age and gender were correlated with OPVH scores $(p<0.05)$, while LDL-C, triglycerides, Apo-B and TC were anti-correlated with OPVHs scores $(p<0.05)$. Multivariate analysis indicated that LDL-C is negatively correlated with OPVHs $(p<0.05)$, and age is positively correlated with OPVHs $(p<0.001)$.
\end{abstract}

Conclusion: In summary, LDL-C was negatively and age was positively associated with OPVHs among Chinese patients in a hospital.

Keywords: MRI, White matter hyperintensity, Occipital periventricular hyperintensities, Low-density lipoprotein cholesterol, Cardiovascular risk factor

\section{Background}

White matter hyperintensities (WMHs), which reflect chronic vascular ischemic diseases, may only represent extreme cases of white matter injury [1]. Previous studies have investigated $\mathrm{WMH}$ progression and its clinical significance [2]. However, the optimal treatment regimen remains to be elucidated [3]. WMH can be categorized as periventricular hyperintensities (PVHs) or deep white matter hyperintensities (DWMHs) [4]. As the severity of the lesions increase, PVHs can extend into the deep white matter (DWM) and may subsequently develop into confluence DWMHs [5]. The precise differences

\footnotetext{
* Correspondence: ddz92@163.com

1 Department of Neurology, Xinqiao Hospital, Third Military Medical

University, No. 183, Xinqiao Street, Chongqing 400037, China

Full list of author information is available at the end of the article
}

between PVHs and DWMHs have not yet been fully explored, though some studies have suggested that their clinical and pathological features differ [6]. PVHs have also been suggested to be associated with brain atrophy, while DWMH is related to cerebrovascular events [7]. PVHs typically have caps around the occipital or frontal horns of the lateral ventricles and a pencil-thin lining or a smooth halo along the side of the lateral ventricles [8]. Thus, WMHs is often parcellated based on anatomy, such as occipital, parietal, frontal, and temporal lobes, as well as in fratentorial and basal ganglia regions, to assess its impact [9]. Such classifications can also reflect the different pathophysiological mechanisms of WMHs, and may be used to inform the design of clinical interventions. In addition, clarifying differences between PVHs and DWMHs may provide insights in the clinical significance 
of WMHs, and differences between pathological aging and normal aging.

Previous studies have reported that age and hypertension are common risk factors for WMHs [10, 11]. In contrast, the results of studies implicating other potential risk factors associated with WMH, such as diabetes mellitus, hyperlipidemia, smoking, high body mass index, vitamin B12 deficiency, and alcohol consumption, were inconsistent [10, 12-17]. Some studies have reported that hyperlipidemia has a protective effect on WMHs, however, these studies included mixed lesions which did not differentiate between early or mild lesions [18]. To our knowledge, the clinical factors contributing to WMHs at a single site have not yet been addressed. With reference to the aforementioned studies, we hypothesized that age is a risk factor while lipids and/or lipoproteins could have a protective effect on WMHs. In this case-control study, we investigated the role of clinical factors in development of pure OPVHs at a single site.

\section{Methods \\ Subjects}

Head magnetic resonance imaging (MRI) images were obtained in a total of 170 subjects from the department of neurology in Xinqiao Hospital, Third Military Medical University (age range: 55-85 years old). Images with Occipital periventricular hyperintensities (OPVHs) were identified according to the inclusion exclusion criteria. Their respective clinical data were then collected, and the patients were examined. The subjects were restricted from vitamin B12 intake for 3 months prior to scanning. Subjects with other diseases that can cause white matter lesions, such as toxic cerebral white matter lesions, multiple sclerosis, atrial fibrillation, progressive multifocal leukoencephalopathy and thyroid disease, were excluded from the study. In addition, we also excluded patients with cerebrovascular disease induced by heart and aorta embolism, atrial fibrillation, valvulopathy, myocardiopathy, endocarditis, left atrioventricular valve stenosis or ventricular aneurysm, vasculitis, familial high homocysteine, infectious diseases, anemia or malignant disease, intracranial tumors, systemic diseases, immune system diseases such as connective tissue or autoimmunity diseases, and those receiving treatments such as radiotherapy, drug chemotherapy and biological therapy.

Subjects were classified into two groups, OPVHs group ( $n=97$ with OPVHs $\geq 1$ and without lesions in other locations) and control group ( $n=73$ with no WMHs) according to the Fazekas scale. No subjects had cerebral infarcts, defined as focal hyperintensities in T2 images. The gender (Gen), age, hypertension (Htn) and history of diabetes mellitus (DM), current smoking (CS) and alcohol use (CAU) were obtained with a patient-administered questionnaire. Total cholesterol (TC), high-density lipoprotein cholesterol
(HDL-C), low-density lipoprotein cholesterol (LDL-C), triglycerides (TG), uric acid (UA), apolipoprotein-A1 (ApoA1) and apolipoprotein-B (Apo-B) were also obtained. Note that this is a retrospective study, and the MRI images were obtained between 2012 October and 2015 October.

\section{MRI protocols}

All MRI data were obtained using a 3.0 Tesla scanner (General Electric, Milwaukee, WI, USA) with a 12-channel head coil. FSE T2-weighted images and FLAIRT1-weighted images were acquired with TE/TR $=112.2 / 3160 \mathrm{~ms}$ and TE/IT/TR $=27.072 / 860 / 1696.68 \mathrm{~ms}$, respectively. All MRI images were acquired with voxel size of $0.4688 \times 0.4688 \times$ $5 \mathrm{~mm} 3,20$ sagittal slices and an in-plane resolution of $512 \times 512$. MRI images were then assessed visually by two neurologist using the Fazekas scale [19].

\section{Data analysis}

Demographic and clinical variables were statistically analyzed using SPSS20 (IBMSPSS, Chicago, USA). Data are presented as mean and standard deviation. Chi-square test and student's $t$-test were used to determine significant differences between frequencies of categories and continuous variables of the groups. In addition, the relationship between these factors and OPVH scores were analyzed using bivariate Pearson Correlation analysis. Subsequently, binomial logistic regression analysis and likelihood ratio test were performed to identify factors independently associated with OPVHs. To access and compare the sensitivity and specificity of using age and LDL-C as diagnostic factors, the receiver operating characteristic (ROC) curve was plotted using OPVHs as positive outcome, and age and LDL-C as diagnostic factors. Subsequently, the Youden Indices were calculated and the maximum Youden Index was used as cut-off value in the ROC curve [20-22]. The cut-off values for age and LDL-C were 57 years and $2.645 \mathrm{mmol} / \mathrm{L}$, respectively. Using these cut-off values, the sensitivity and specificity were obtained. Finally, the area under ROC curve was quantified and statistically analyzed using SPSS. Results were considered significant when $P<0.05$.

\section{Results \\ T2-weighted MRI changes in OPVH patients}

Figure 1 shows two typical T2-weighted MRI images of a control (Fig. 1a) and a OPVHs patient (Fig. 1b). Highsignal intensities were observed on the T2-weighted images of OPVHs patients. In addition, no cerebral infarcts were observed on the T2-weighted images in all subjects.

\section{Clinical variables and OPVHs using univariate analysis}

Table 1 summarizes the differences between the OPVH patients and controls. The OPVH patients were significantly older $(p<0.001)$, with lower TC $(p<0.05)$, 


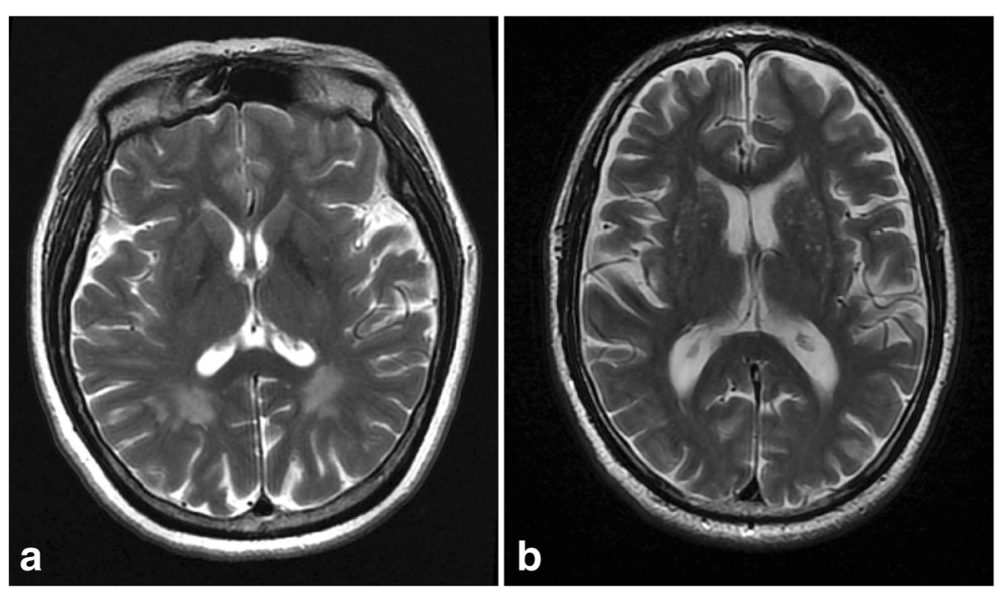

Fig. 1 Typical T2-weighted MRI images a control and a OPVHs patient. Two typical T2-weighted MRI images of a control (a) and a OPVHs patient (b). High-signal intensities are observed on the T2-weighted image of the OPVHs patient. In addition, no cerebral infarcts were observed on the T2-weighted images in any subjects

LDL-C $(p<0.001)$ and Apo-B $(p<0.05)$ levels. Table 2 summarizes the correlations between OPVHs and potential risk factors. Spearman correlation analysis indicated that age $(p<0.001)$ and gender $(p<0.05)$ were correlated with OPVHs, while LDL-C $(p<0.001)$, TG $(p<0.05)$, Apo-B $(p<0.001)$ and TC $(p<0.05)$ were anti-correlated with OPVHs.

\section{Clinical variables and OPVHs using multivariate analysis} Binomial logistic regression analysis indicated that age $(p<0.001)$ was positively correlated with OPVHs, while

Table 1 Clinical factors differing between OPVHs and CN

\begin{tabular}{|c|c|c|c|c|}
\hline Group & OPVHS & CN & $x^{2 / t}$ & $p$ \\
\hline $\bar{n}$ & 97.00 & 73.00 & / & 1 \\
\hline OPVH Scores & $2.72(0.54)$ & $0.00(0.00)$ & / & / \\
\hline Gen $(n, \% \text { male })^{1}$ & $61(62.89)$ & $35(47.95)$ & 3.78 & 0.05 \\
\hline Age (years) ${ }^{2}$ & $71.79(8.29)$ & $68.9(7.91)$ & -4.87 & $<0.001^{*}$ \\
\hline $\operatorname{CS}(n, \%)^{1}$ & $24(24.74)$ & $21(28.77)$ & 0.35 & 0.56 \\
\hline $\operatorname{CAU}(n, \%)^{1}$ & $21(21.65)$ & 14(19.18) & 0.16 & 0.69 \\
\hline $\operatorname{Htn}(n, \%)^{1}$ & $47(48.45)$ & $26(35.62)$ & 2.80 & 0.09 \\
\hline $\operatorname{DM}(n, \%)^{1}$ & $18(18.56)$ & $8(10.96)$ & 1.86 & 0.17 \\
\hline $\mathrm{TC}^{2}$ & $4.61(1.07)$ & $4.81(0.96)$ & 2.05 & $0.04^{*}$ \\
\hline $\mathrm{TG}^{2}$ & $1.44(0.76)$ & $1.66(1.17)$ & 1.48 & 0.14 \\
\hline $\mathrm{LDL}_{-} \mathrm{C}^{2}$ & $2.51(0.63)$ & $2.83(0.68)$ & 3.20 & $<0.001^{*}$ \\
\hline HDL_C ${ }^{2}$ & $1.34(0.32)$ & $1.29(0.30)$ & -0.95 & 0.34 \\
\hline$U A^{2}$ & $289(75.30)$ & $277.75(67.33)$ & -1.01 & 0.31 \\
\hline$A p o-A 1^{2}$ & $1.30(0.31)$ & $1.25(0.33)$ & -1.01 & 0.31 \\
\hline Apo-B ${ }^{2}$ & $0.84(0.24)$ & $0.91(0.23)$ & 2.24 & $0.03^{*}$ \\
\hline
\end{tabular}

Continuous variables are presented as mean (standard deviation) and compared using Student's $t$-test, while categorical variables are presented as percent and compared between groups using the chi-square test,. 1, $2 *$ denotes Chi-square test, Student's $t$-test and $p<0.05$, respectively
LDL-C $(p<0.05)$ was negatively correlated with OPVHs (Table 3). For ROC analysis, the sensitivity and specificity of age as a diagnostic factor were 0.986 and 0.041 , respectively. On the other hand, the sensitivity and specificity of LDL-C as a diagnostic factor were 0.630 and 0.639 , respectively. The ROC indicated that age $(p<0.001)$ and LDL-C $(p<0.01)$ differed significantly between OPVH patients and healthy controls (Table 4). These results suggest that OPVHs and age are positively associated, while OPVHs and LDL-C are negatively associated, respectively. It should be noted that LDL-C was a better predictor of OPVHs than age, based on the area under the curve (Fig. 2).

Table 2 Correlation of clinical factors and OPVHs

\begin{tabular}{lll}
\hline Risk factors & \multicolumn{1}{l}{$R$} \\
\hline Age & 0.36 & $<0.001^{*}$ \\
Gen & 0.18 & $0.02^{*}$ \\
Htn & 0.12 & 0.12 \\
DM & 0.07 & 0.34 \\
CAU & 0.05 & 0.51 \\
CS & -0.04 & 0.59 \\
UA & 0.08 & 0.30 \\
LDL-C & -0.25 & $<0.001^{*}$ \\
HDL-C & 0.07 & 0.35 \\
TG & -0.17 & $0.03^{*}$ \\
Apo-A1 & 0.07 & 0.39 \\
Apo-B & -0.24 & $0.00^{*}$ \\
TC & -0.17 & $0.03^{*}$ \\
\hline
\end{tabular}

Statistical correlations were determined by two-tailed bivariate Pearson correlation coefficient test with all risk factors as independent variables and the OPVH scores as dependent variables. ${ }^{*}$ denotes $p<0.05$ 
Table 3 Binomial logistic regression analysis of Independent factors for OPVHs

\begin{tabular}{llllcc}
\hline $\begin{array}{l}\text { Risk } \\
\text { factors }\end{array}$ & B & -value & OR & \multicolumn{2}{c}{$95 \%$ C. I. of OR } \\
\cline { 5 - 6 } & & & & Lower Bound & Up Bound \\
\hline Age & 0.09 & $<0.001^{*}$ & 1.09 & 1.04 & 1.14 \\
Gen & 0.53 & 0.16 & 1.70 & 0.82 & 3.52 \\
TC & 0.43 & 0.26 & 1.53 & 0.73 & 3.20 \\
TG & -0.18 & 0.33 & 0.84 & 0.59 & 1.20 \\
LDL-C & -0.99 & $0.03^{*}$ & 0.37 & 0.16 & 0.89 \\
Apo-B & -0.17 & 0.86 & 0.84 & 0.13 & 5.55
\end{tabular}

$P$-values were obtained using OPVHs as positive outcome and Age, Gen, TC, TG, LDL-C, Apo-B as independent variables by binomial Logistic regression analysis. * denotes $p<0.05$

\section{Discussion}

White matter hyperintensities (WMHs) are thought to reflect chronic cerebral small vessel diseases, and can be easily detected using MRI. In previous studies, age and hypertension were reported to be the most common risk factors for WMHs [10, 11], while the role of other potential risk factors, such as diabetes mellitus, hyperlipidemia, smoking, high body mass index, B12 deficiency, and alcohol were reported inconsistently [10, 12-17]. Our results demonstrate that age was strongly correlated with the occurrence of OPVHs, which is consistent with previous studies. In addition, LDL-C was anti-correlated with OPVHs. These results indicate that age was positively correlated to OPVHs, while LDL-C was negatively correlated with OPVHs.

Receiver operating characteristic curve (ROC), also known as susceptibility curve, sensitivity curve, or diagnostic curve, can reflect both sensitivity and specificity. The ROC curve is based on the probability of true positive rate versus false positive rate. Note that the closer the ROC curve is to the upper left, the higher the accuracy of the test. In other words, the point of the ROC curve closest to the upper left corner is the best threshold to be used with a minimal number of false positives and false negatives. The advantages of ROC curve are as follows. First, it can easily identify the diagnostic ability using an optimal diagnostic threshold. Second, ROC curve can differentiate two or more different diagnostic tests by plotting the ROC curves of each trial or diagnostic test in the same plot to visually identify the advantages and disadvantages of these diagnoses. Third, it

Table 4 Diagnostic strength of independent factors for OPVHs

\begin{tabular}{lllcc}
\hline Variable & Area & $p$-value & \multicolumn{2}{c}{$95 \%$ C. I. of Area } \\
\cline { 4 - 5 } & & & Lower Bound & Upper Bound \\
\hline Age & 0.290 & $<0.001^{*}$ & 0.211 & 0.368 \\
LDL-C & 0.642 & $0.002^{*}$ & 0.558 & 0.726
\end{tabular}

$P$-values and the area under the curve were obtained using OPVHs as positive outcome with age and LDL-C as diagnostic factor. * denotes $p<0.05$ is possible to compare the area under the ROC curve (AUC) for each method, which the larger that AUC the better, to identify the best diagnostic method [21, 23]. In order to study the sensitivity and specificity of LDL-C in diagnosing OPVHs, we performed ROC curve analysis. Our results indicate that LDL-C was a better predictor of OPVHs than age, since the sum of sensitivity and specificity of LDL-C is higher than that of age. Despite the advantages of ROC curve analysis, it should be noted that high AUC values may actually have poor overall accuracy in some cases.

LDL-C is widely recognized as a risk factor for stroke $[24,25]$, and lipid-lowering therapies have demonstrated benefits in stroke prevention and prognosis [26, 27]. Statin treatment may protect the vessels of the brain and increase survival rate. However, previous studies have suggested that statin treatment may deteriorate WMHs [28]. We observed that higher LDL-C levels were associated with lower severity of OPVHs, which is consistent with previous findings $[29,30]$. Our results also highlighted other less influential factors, with LDL-C being a more influential factor than age. Although the mechanisms underlying the anti-correlation between LDL-C and OPVHs are not fully understood, we speculate that cholesterol may play an important role in neuron repair and remodeling in the central nervous system [31].

Previous studies of the effect of pravastatin on the progression of ischemic brain lesions were evaluated using MRI longitudinally [32]. After treatment, no difference in lesion progression was observed between the pravastatintreated and placebo groups. In another study involving participants with long-standing type 2 diabetes at a high risk for cardiovascular events, decreased LDL-C levels did not produce significant cognitive changes at 40 months of follow-up [33]. These studies suggest that lowering cholesterol did not benefit the white matter or cognitive functions. However, our results suggest that decreasing LDL-C could deteriorate WMHs. It should be noted that our study focused on mild OPVHs, while previous studies included more severe OPVHs. This might explain the discrepancy between our results and those of previous studies, since early mild lesions should have less influence factors. Our study also provides insights that may inform development of simple preventive measures.

WMHs are largely divided into PVHs and deep DWMHs [4], but the precise difference between PVHs and DWMHs is yet to be fully elucidated, with both types strongly associated with age [34]. Previous studies have suggested that the clinical and pathological features of these two types of WMHs are diverse [6]. PVHs may be more strongly affected by additional factors related to aging, such as hypotension, hypoperfusion, and atrophy [35-37], whereas DWMHs may be associated with cerebrovascular events [7]. Previous studies indicate that a 


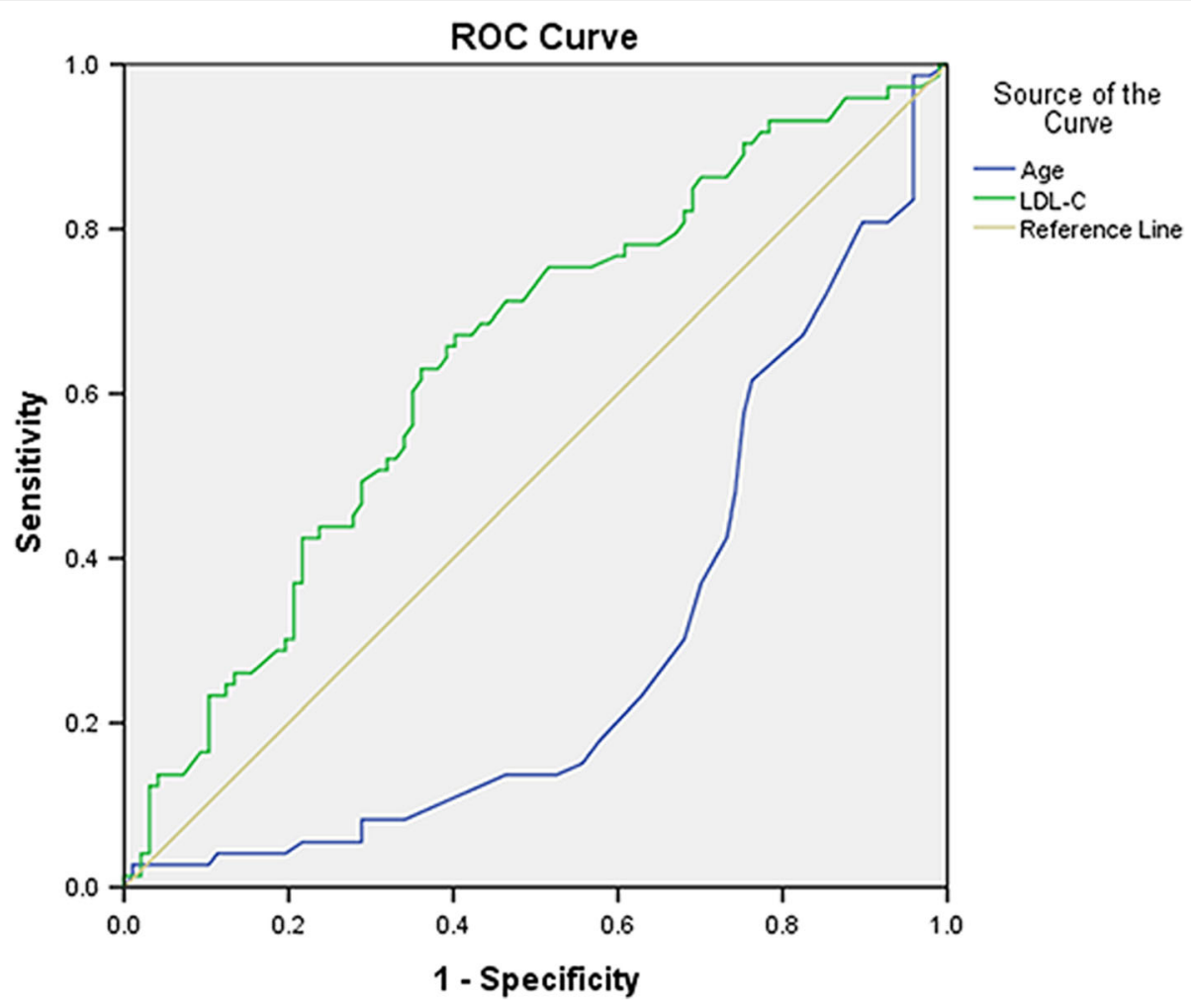

Fig. 2 Receiver operating characteristic curve using age and LDL-C as diagnostic factors for OPVHs. ROC were obtained using OPVHs as positive outcome and age and LDL-C as diagnostic factors. It should be noted that the diagnostic strength of LDL-C, calculated using on the area under the curve, was greater than that of age for OPVHs

reduction in total cerebral blood flow is associated with increased PVH volume but not DWMH volume [38]. It is also known that cholesterol can play a fundamental role in the development of the central nervous system and in the creation and maintenance of new synapses, which may be related to OPVHs [31, 39, 40]. Hypoperfusion may reduce delivery of nutrients to the white matter in the brain [41]. The periventricular white matter extends 3 to $13 \mathrm{~mm}$ around the periventricle [42], the blood supply of this area is provided by choroidal arteries or the terminal branch of lenticulostriate arteries of subependymal artery [43], anastomose of the vessels is sparse or missing, and the area is prone to ischemia during cerebral ischemia or hypoperfusion [41]. Surprisingly, accumulating evidence suggests that it is low rather than high levels of circulating cholesterol that may contribute to the risk of primary intracerebral hemorrhage [44] and to a higher mortality rate in these patients [45]. Furthermore, it has been shown that higher cholesterol levels are associated with less severe WMHs [46-48]. This could explain the role of elevated cholesterol levels and a better response to an acute injury such as stroke, as well as better responses to chronic cerebral injury (such as the processes involved in WMH development). Our results, along with these previous studies, support the hypothesis that hypercholesterolemia may play a protective role in cerebral smallvessel disease [49], whereas hypocholesterolemia appears to impair endothelial reparative processes [50]. Both lower LDL-C and severity of WMH have a significant heritability component [51, 52]. Combined with previous research, our results show that higher cholesterol was associated with reduced OPVHs, and relatively higher cholesterol might be associated with better health status in late life [53]. It should be noted that abnormally high cholesterol levels are not associated with better health. Our study provides a basis for the selection of populations that require intervention and intervention methods, in particular the widespread use of statins should be carefully reviewed. Our results also offer a model for the investigation of WMH pathogenesis in future animal studies.

The limitations of this study relate first to its retrospective design, and second to the small sample size. A specifically designed, randomized, controlled prospective population-based study may ultimately clarify the role of LDL-C in OPVHs, and is warranted in future studies. Our ROC analysis revealed that using age as the diagnostic factor of OPVHs was mathematically correct, however, it may have few implications as the results showed a low specificity. Future studies may investigate 
other parameters as diagnostic factors of OPVHs. Also, our findings are only from a Chinese hospital and do not rule out the possibility of selective bias or sampling error. In addition, future studies may encompass the mechanisms on how LDL-C affects OPVHs using animal models. Although body mass index and VB12 are associated with OPVHs, how these factors exactly affect OPVHs remains to be elucidated.

\section{Conclusions}

LDL-C was negatively, and age was positively associated with OPVHs among Chinese patients in a hospital.

\section{Abbreviations}

Apo-A1: Apolipoprotein-A; Apo-B: Apolipoprotein-B; C. I: Confidence interval; CAU: Current alcohol use; CN: Controls; CS: Current smoking; DM: Diabetes mellitus; Gen: Gender; HDL-C: High density lipoprotein cholesterol; Htn: Hypertension; LDL-C: Low density lipoprotein cholesterol; OPVHs: Occipital periventricular hyperintensities; ROC: Receiver operating characteristic; TC: Total cholesterol; TG: Triglyceride; UA: Uric acid: WMHs: White matter hyper intensities

\section{Acknowledgements}

This study was supported by a grant from Chongqing Science and Technology project, People's Republic of China (cstc2012gg-yyjs10009).

\section{Funding}

Not applicable.

\section{Availability of data and materials}

The datasets used and/or analysed during the current study available from the corresponding author on reasonable request.

\section{Authors' contributions}

DZD performed MRI data assessment, statistical analysis and drafted the manuscript. LS carried out the demographic and cardiovascular risk factor data collection and screened the subjects. CC and TSS participated in the MRI data acquisition and screening subjects. JZ conceived of the study, and participated in its design and coordination and helped to draft the manuscript. All authors read and approved the final manuscript.

\section{Competing interests}

The authors declare that they have no competing interests.

\section{Consent for publication}

All participants provided consent for publication of their data.

\section{Ethics approval and consent to participate}

This study was approved by the medical ethics committee of Xinqiao Hospital, Third Military Medical University, Chongqing, China. All participants provided informed consent for participation in the study.

\section{Author details \\ ${ }^{1}$ Department of Neurology, Xinqiao Hospital, Third Military Medical University, No. 183, Xinqiao Street, Chongqing 400037, China. ${ }^{2}$ Department of Radiology, Xinqiao Hospital, Third Military Medical University, No. 183, Xinqiao Street, Chongqing 400037, China.}

Received: 6 May 2016 Accepted: 20 February 2017

Published online: 27 February 2017

\section{References}

1. Ishihara N, Naritomi H, Meyer JS, Dodson RF, Deshmukh VD. Differences in the time course of regional cerebral hemo-dynamics of gray and white matter during experimental hypertension. J Neurol Sci. 1978;38:97-111.

2. Abraham HM, Wolfson L, Moscufo N, Guttmann CR, Kaplan RF, White WB. Cardiovascular risk factors and small vessel disease of the brain: Blood pressure, white matter lesions, and functional decline in older persons. J Cereb Blood Flow Metab. 2016:36:132-42.

3. de Leeuw FE, Barkhof F, Scheltens P. Progression of cerebral white matter lesions in Alzheimer's disease: a new window for therapy? J Neurol Neurosurg Psychiatry. 2005;76:1286-8.

4. Katsumata $T$, Otori $T$, Nishiyama $Y$, Okubo $S$, Nishiyama $Y$, Nagayama $H$, Ueda M, Utsumi K, Yamazaki M, Komaba Y, et al. Correlation between insulin resistance and white matter lesions among non-diabetic patients with ischemic stroke. Neurol Res. 2010;32:743-7.

5. Enzinger C, Fazekas F, Ropele S, Schmidt R. Progression of cerebral white matter lesions - clinical and radiological considerations. J Neurol Sci. 2007;257:5-10.

6. Holland CM, Smith EE, Csapo I, Gurol ME, Brylka DA, Killiany RJ, Blacker D, Albert MS, Guttmann CR, Greenberg SM. Spatial distribution of white-matter hyperintensities in Alzheimer disease, cerebral amyloid angiopathy, and healthy aging. Stroke. 2008;39:1127-33.

7. Barber R, Gholkar A, Scheltens P, Ballard C, McKeith IG, O'Brien JT. MRI volumetric correlates of white matter lesions in dementia with Lewy bodies and Alzheimer's disease. Int J Geriatr Psychiatry. 2000;15:911-6.

8. Kawamura J, Terayama Y, Takashima S, Obara K, Pavol MA, Meyer JS, Mortel KF, Weathers S. Leuko-araiosis and cerebral perfusion in normal aging. Exp Aging Res. 1993:19:225-40

9. DeCarli C, Massaro J, Harvey D, Hald J, Tullberg M, Au R, Beiser A, D’Agostino R, Wolf PA. Measures of brain morphology and infarction in the framingham heart study: establishing what is normal. Neurobiol Aging. 2005;26:491-510.

10. Liao D, Cooper L, Cai J, Toole J, Bryan N, Burke G, Shahar E, Nieto J, Mosley $T$, Heiss $G$. The prevalence and severity of white matter lesions, their relationship with age, ethnicity, gender, and cardiovascular disease risk factors: the ARIC Study. Neuroepidemiology. 1997;16:149-62.

11. de Leeuw FE, de Groot JC, Oudkerk M, Witteman JC, Hofman A, van Gijn J, Breteler MM. Hypertension and cerebral white matter lesions in a prospective cohort study. Brain. 2002;125:765-72.

12. Breteler MM, van Swieten JC, Bots ML, Grobbee DE, Claus JJ, van den Hout $J$ H, van Harskamp F, Tanghe HL, de Jong PT, van Gijn J, et al. Cerebral white matter lesions, vascular risk factors, and cognitive function in a populationbased study: the Rotterdam study. Neurology. 1994;44:1246-52.

13. Hickie I, Naismith S, Ward PB, Scott E, Mitchell P, Wilhelm K, Parker G. Vascular risk and low serum B12 predict white matter lesions in patients with major depression. J Affect Disord. 2005:85:327-32.

14. Jeerakathil T, Wolf PA, Beiser A, Massaro J, Seshadri S, D'Agostino RB, DeCarli C. Stroke risk profile predicts white matter hyperintensity volume: the Framingham study. Stroke. 2004;35:1857-61.

15. Longstreth Jr WT. Clinical correlates of white matter findings on cranial magnetic resonance imaging of 3301 elderly people. The cardiovascular health study. Stroke. 1996;27:1274-82.

16. Murray AD, Staff RT, Shenkin SD, Deary IJ, Starr JM, Whalley LJ. Brain white matter hyperintensities: relative importance of vascular risk factors in nondemented elderly people. Radiology. 2005;237:251-7.

17. Stenset V, Johnsen L, Kocot D, Negaard A, Skinningsrud A, Gulbrandsen P, Wallin A, Fladby T. Associations between white matter lesions, cerebrovascular risk factors, and low CSF Abeta42. Neurology. 2006;67:830-3.

18. Chowdhury MH, Nagai A, Bokura H, Nakamura E, Kobayashi S, Yamaguchi S. Age-related changes in white matter lesions, hippocampal atrophy, and cerebral microbleeds in healthy subjects without major cerebrovascular risk factors. J Stroke Cerebrovasc Dis. 2011;20:302-9.

19. Fazekas F, Chawluk JB, Alavi A, Hurtig HI, Zimmerman RA. MR signal abnormalities at $1.5 \mathrm{~T}$ in Alzheimer's dementia and normal aging. AJR Am J Roentgenol. 1987;149:351-6.

20. Rucker G, Schumacher M. Summary ROC curve based on a weighted Youden index for selecting an optimal cutpoint in meta-analysis of diagnostic accuracy. Stat Med. 2010;29:3069-78.

21. Hajian-Tilaki K. Receiver operating characteristic (ROC) curve analysis for medical diagnostic test evaluation. Caspian J Intern Med. 2013;4:627-35.

22. Nakas CT, Dalrymple-Alford JC, Anderson TJ, Alonzo TA. Generalization of Youden index for multiple-class classification problems applied to the assessment of externally validated cognition in Parkinson disease screening. Stat Med. 2013:32:995-1003.

23. Metz CE. ROC analysis in medical imaging: a tutorial review of the literature. Radiol Phys Technol. 2008:1:2-12

24. Tirschwell DL, Smith NL, Heckbert SR, Lemaitre RN, Longstreth Jr WT, Psaty BM. Association of cholesterol with stroke risk varies in stroke subtypes and patient subgroups. Neurology. 2004;63:1868-75. 
25. Gorelick PB, Schneck M, Berglund LF, Feinberg W, Goldstone J. Status of lipids as a risk factor for stroke. Neuroepidemiology. 1997;16:107-15.

26. Stroke Prevetion by Aggressive Reduction in Cholestrol Levels I, Karam JG, Loney-Hutchinson L, McFarlane SI. High-dose atorvastatin after stroke or transient ischemic attack: the stroke prevention by aggressive reduction in cholesterol levels (SPARCL) investigators. J Cardiometab Syndr. 2008;3:68-9.

27. Alvarez-Sabin J, Huertas R, Quintana M, Rubiera M, Delgado P, Ribo M, Molina CA, Montaner J. Prior statin use may be associated with improved stroke outcome after tissue plasminogen activator. Stroke. 2007;38:1076-8.

28. Longstreth WT, Arnold AM, Beauchamp NJ, Manolio TA, Lefkowitz D, Jungreis C, Hirsch CH, O'Leary DH, Furberg CD. Incidence, manifestations, and predictors of worsening white matter on serial cranial magnetic resonance imaging in the elderly - the cardiovascular health study. Stroke. 2005;36:56-61.

29. Jimenez-Conde J, Biffi A, Rahman R, Kanakis A, Butler C, Sonni S, Massasa E, Cloonan L, Gilson A, Capozzo K, et al. Hyperlipidemia and reduced white matter hyperintensity volume in patients with ischemic stroke. Stroke. 2010;41:437-42.

30. Ichikawa H, Mukai M, Ohno H, Shimizu Y, Itaya K, Kawamura M. Deep white matter hyperintensities, decreased serum Low-density lipoprotein, and dilative large arteriopathy. J Stroke \& Cerebrovasc Dis. 2012;21:225-30.

31. Dietschy JM. Central nervous system: cholesterol turnover, brain development and neurodegeneration. Biol Chem. 2009:390:287-93.

32. ten Dam VH. Effect of pravastatin on cerebral infarcts and white matter lesions. Neurology. 2005;64:1807-9.

33. Williamson JD. Cognitive function and brain structure in persons with type 2 diabetes mellitus after intensive lowering of blood pressure and lipid levels: a randomized clinical trial. JAMA Intern Med. 2014;174:324-33.

34. Pantoni L, Fierini F, Poggesi A, Grp LS. Impact of cerebral white matter changes on functionality in older adults: an overview of the LADIS study results and future directions. Geriatr Gerontol Int. 2015;15:10-6.

35. Wang TJ, Massaro JM, Levy D, Vasan RS, Wolf PA, D'Agostino RB, Larson MG, Kannel WB, Benjamin EJ. A risk score for predicting stroke or death in individuals with new-onset atrial fibrillation in the community: the Framingham heart study. JAMA. 2003;290:1049-56.

36. Wen W, Sachdev P. The topography of white matter hyperintensities on brain MRI in healthy 60- to 64-year-old individuals. Neuroimage. 2004;22:144-54.

37. Wen W, Sachdev PS, Li JJ, Chen XH, Anstey KJ. White matter hyperintensities in the forties: their prevalence and topography in an epidemiological sample aged 44-48. Hum Brain Mapp. 2009;30:1155-67.

38. van den Heuvel DM, ten Dam VH, de Craen AJ, Admiraal-Behloul F, Olofsen H, Bollen EL, Jolles J, Murray HM, Blauw GJ, Westendorp RG, van Buchem MA. Increase in periventricular white matter hyperintensities parallels decline in mental processing speed in a non-demented elderly population. J Neurol Neurosurg Psychiatry. 2006;77:149-53.

39. Mauch DH, Nagler K, Schumacher S, Goritz C, Muller EC, Otto A, Pfrieger FW. CNS synaptogenesis promoted by glia-derived cholesterol. Science. 2001; 294:1354-7.

40. Goritz C, Mauch DH, Pfrieger FW. Multiple mechanisms mediate cholesterolinduced synaptogenesis in a CNS neuron. Mol Cell Neurosci. 2005;29:190-201.

41. Choi JY, Cui Y, Kim BG. Interaction between hypertension and cerebral hypoperfusion in the development of cognitive dysfunction and white matter pathology in rats. Neuroscience. 2015;303:115-25.

42. van Harten B, Oosterman JM, van Loon BJ P, Scheltens $P$, Weinstein HC. Brain lesions on MRI in elderly patients with type 2 diabetes mellitus. Eur Neurol. 2007;57:70-4.

43. Fazekas F, Kleinert R, Offenbacher $\mathrm{H}$, Schmidt R, Kleinert G, Payer F, Radner $\mathrm{H}$, Lechner H. Pathologic correlates of incidental MRI white matter signal hyperintensities. Neurology. 1993:43:1683-9.

44. Woo D, Kissela BM, Khoury JC, Sauerbeck LR, Haverbusch MA, Szaflarski JP, Gebel JM, Pancioli AM, Jauch EC, Schneider A, et al. Hypercholesterolemia, HMG-CoA reductase inhibitors, and risk of intracerebral hemorrhage: a case-control study. Stroke. 2004:35:1360-4.

45. Roquer J, Rodriguez Campello A, Gomis M, Ois A, Munteis E, Bohm P. Serum lipid levels and in-hospital mortality in patients with intracerebral hemorrhage. Neurology. 2005;65:1198-202.

46. Enzinger C, Fazekas F, Matthews PM, Ropele S, Schmidt H, Smith S, Schmidt R. Risk factors for progression of brain atrophy in aging: six-year follow-up of normal subjects. Neurology. 2005;64:1704-11.

47. Soljanlahti S, Autti T, Lauerma K, Raininko R, Keto P, Turtola H, Vuorio AE. Familial hypercholesterolemia patients treated with statins at no increased risk for intracranial vascular lesions despite increased cholesterol burden and extracranial atherosclerosis. Stroke. 2005;36:1572-4.
48. Smith JA, Turner ST, Sun YV, Fornage M, Kelly RJ, Mosley TH, Jack CR, Kullo IJ, Kardia SL. Complexity in the genetic architecture of leukoaraiosis in hypertensive sibships from the GENOA Study. BMC Med Genomics. 2009;2:16.

49. Etherton MR, Wu O, Rost NS. Recent Advances in Leukoaraiosis: White Matter Structural Integrity and Functional Outcomes after Acute Ischemic Stroke. Curr Cardiol Rep. 2016;18:123.

50. Rodriguez C, Slevin M, Rodriguez-Calvo R, Kumar S, Krupinski J, Tejerina T, Martinez-Gonzalez J. Modulation of endothelium and endothelial progenitor cell function by Low-density lipoproteins: implication for vascular repair, angiogenesis and vasculogenesis. Pathobiology. 2009;76:11-22.

51. Austin MA, Edwards KL, McNeely MJ, Chandler WL, Leonetti DL, Talmud PJ, Humphries SE, Fujimoto WY. Heritability of multivariate factors of the metabolic syndrome in nondiabetic Japanese americans. Diabetes. 2004;53:1166-9.

52. Atwood LD, Wolf PA, Heard-Costa NL, Massaro JM, Beiser A, D'Agostino RB, DeCarli C. Genetic variation in white matter hyperintensity volume in the Framingham study. Stroke. 2004;35:1609-13.

53. Mielke MM, Zandi PP, Sjogren M, Gustafson D, Ostling S, Steen B, Skoog I. High total cholesterol levels in late life associated with a reduced risk of dementia. Neurology. 2005;64:1689-95.

\section{Submit your next manuscript to BioMed Central and we will help you at every step:}

- We accept pre-submission inquiries

- Our selector tool helps you to find the most relevant journal

- We provide round the clock customer support

- Convenient online submission

- Thorough peer review

- Inclusion in PubMed and all major indexing services

- Maximum visibility for your research

Submit your manuscript at www.biomedcentral.com/submit
Ciomed Central 